\title{
Cribriform Carcinoma of Tongue and Minor Salivary Glands- A Case Report
}

\author{
Sabah Nayef Nemri ${ }^{1}$, Sohaila Fatima ${ }^{2 *}$ and Nazima Haider ${ }^{2}$ \\ ${ }^{1}$ Deptt. of Laboratory Medicine, Aseer Central Hospital, Abha, KSA \\ ${ }^{2}$ Deptt. of Pathology, King Khalid University, Abha, KSA
}

\begin{abstract}
Cribriform adenocarcinoma of tongue and minor salivary gland is a rare low grade malignant tumor . It is considered polymorphous low grade adenocarcinoma of salivary glands with unique features. We present a case of 48 years old male with a sublingual mass who was diagnosed as cribriform carcinoma.
\end{abstract}

Keywords: Cribriform Adenocarcinoma, Tongue and Minor Salivary Gland , Polymorphous Low Grade Adenocarcinoma

\section{Introduction}

Cribriform adenocarcinoma of tongue and minor salivary gland(CATMSG) is a rare low grade malignant tumor first described in 1999 [1]. In the recent world health organization (WHO) classification of head and neck tumors it is included in the category of polymorphous low grade adenocarcinoma (PLGA) of salivary gland tumors [2]. Here we present a case of CATMSG located at the base of tongue in a 48 years old male.

\section{Case Report}

A 48 year old male presented with swelling below the tongue of 4 months duration and difficulty in swallowing for 15 days. On examination a mass around $3 \mathrm{~cm}$ was noted sublingually. Incisonal biopsy was done and sections showed a tumor composed of small glandular structures with cribriform pattern lined by cells exhibiting mild nuclear enlargement and pleomorphism . Focal squamous differentiation, hyaline material and occasional small foci of myxoid and chondroid material were seen. No mitotic activity was noted. (Figure 1A,B). Immunohistochemical analyses revealed cytokeratin7, pancytokeratin, vimentin ,S100 positivity ( Figure 2A,B,C,D )and calponin , GFAP negativity. A diagnosis of cribriform carcinoma of tongue was made. The patient was advised complete resection of the tumor with wide surgical margin.

\section{Discussion}

CATMSG is extremely rare representing only $0.5 \%$ of salivary gland tumors [3]. It was originally described as cribriform adenocarcinoma of the tongue in 1999[1]. Later on similar tumors were described in soft palate, retromolar trigone , upper lip, floor of the mouth, lingual tonsils $[3,4,5]$ and this entity was renamed as cribriform adenocarcinoma of minor salivary glands [3].However latest WHO classification considers it as a variant of PLGA [2]. It is a low-grade salivary gland tumor with predominant involvement of base of tongue [6]. The review of cases showed slight female predominance with mean age of the patients being 56.8 years [7]. Our patient was a 48 years old male .

Grossly, the tumors are unencapsulated, white-tan to grey in color, and hard in consistency with no necrosis and hemorrhage. Histopathologically, the tumor is almost always covered by an intact squamous epithelium devoid of ulceration or dysplasia. The tumors themselves are composed predominantly of cribriform to microcribriform and solid structures in variable proportions [1]. The most prominent feature are overlapping pale nuclei, optically clear, vesicular with a ground glass appearance . Cellular atypia is mild and with rare mitotic figures . Generally, there are one to three small inconspicuous nucleoli. The cytoplasm is clear to eosinophilic. Cytologically, all the tumors are composed of one cell type. The overall morphology of the tumor with focal papillary growth and with overlapping clear "Orphan Annie eye-like nuclei" is similar to papillary thyroid carcinoma [7].

Ultrastructurally all tumor areas reveal a microcribriform arrangement. An unusual feature is that many of the secretory cells display the apical microvilli alongwith groups of microfilaments in the cytoplasm thus having features of hybrid myoepithelial-secretory cells and thus "secretory myoepithelia"[1,6].

CATMSG had lymph node metastases in 19/31 cases at the time of diagnosis with no case showing distant metastasis 


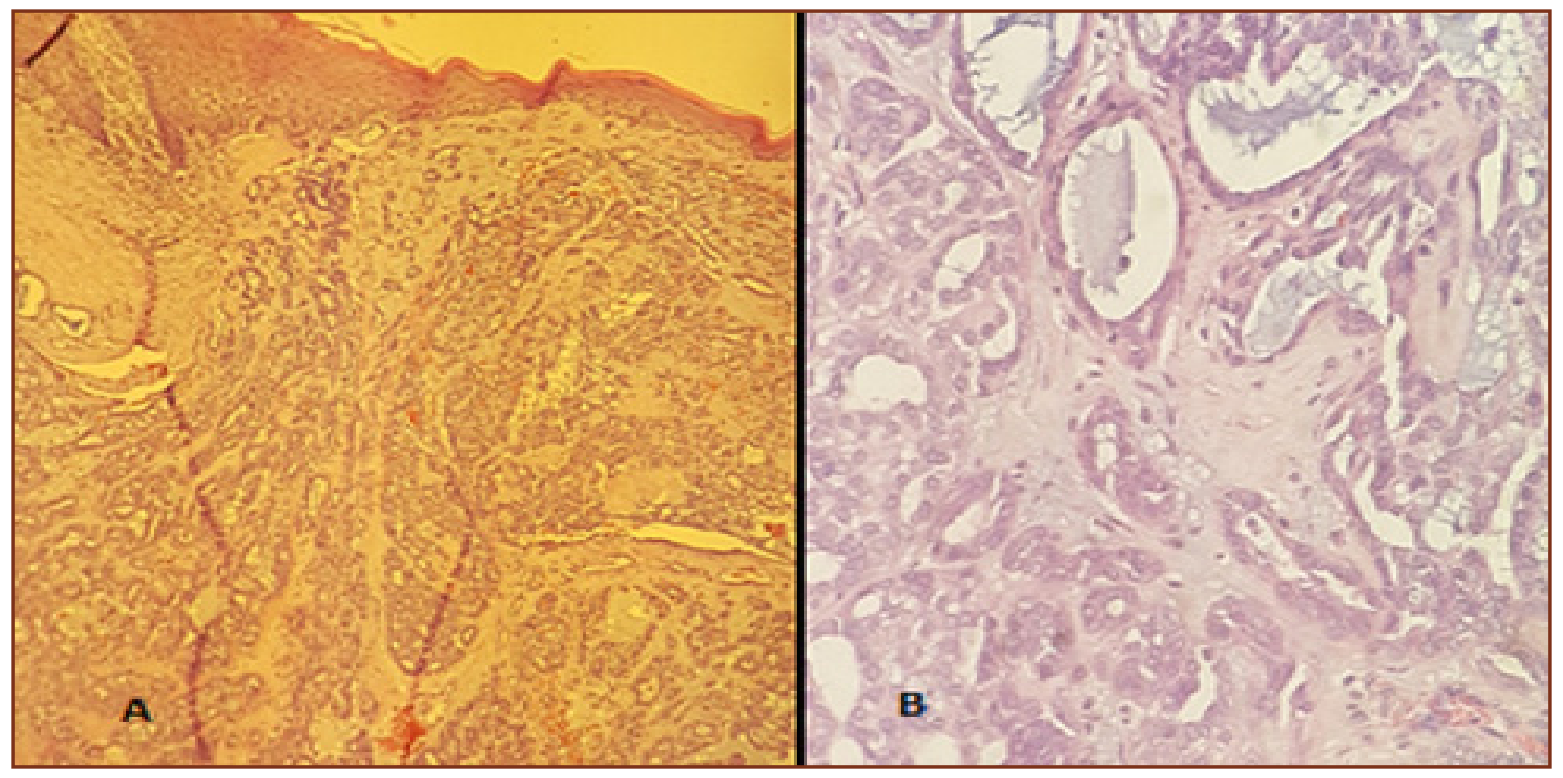

Fig. 1A: Section shows the tumor covered by an intact squamous epithelium devoid of ulceration or dysplasia . The tumors themselves are composed predominantly of cribriform to microcribriform and solid structures. B. The tumor cells have overlapping pale nuclei and the cytoplasm is clear to eosinophilic..

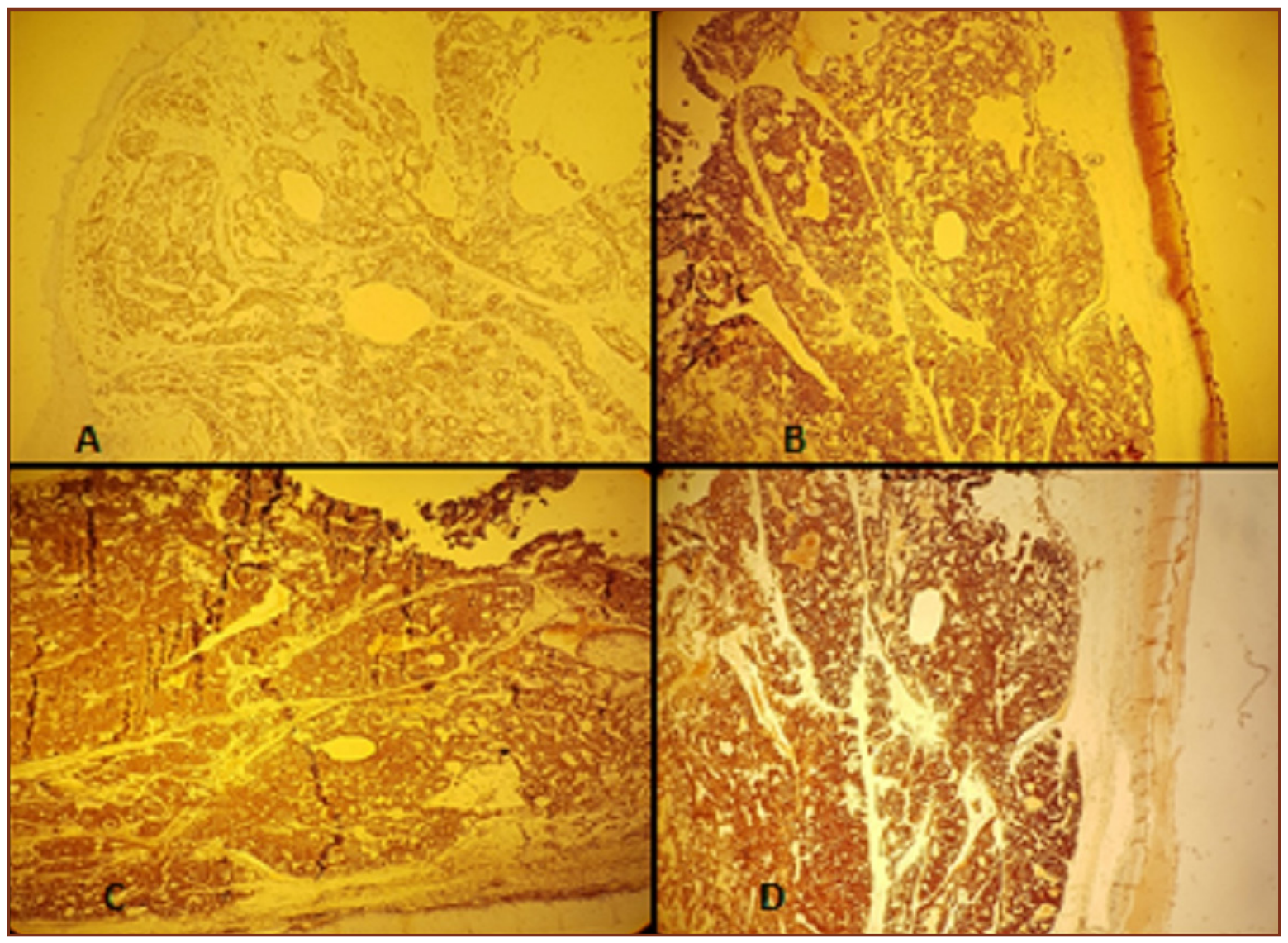

Fig. 2: Immunohistochemical study A.Showing cytokeratin 7 positivity in malignant cells (Cytokeratin 7x20X)B. Showing pancytokeratin positivity in malignant cells(pancytokeratin $\mathrm{x} 20 \mathrm{X}$ ) C.Vimentin positivity in malignant cells(Vimentin x20X). D: S100 positivity in malignant cells(S100x20X). 
[7]. $80 \%$ of CATMSG harbor recurrent translocations in the PRKD1-3 gene family but it is not specific for this tumor as PLGA have also been shown to be positive for it [3]. No mutations of RET, BRAF, K-RAS, H-RAS, and N-RAS proto-oncogenes have been detected [8] .

CATMSG react strongly with antibodies to cytokeratin markers AE1-3, CAM5.2, CK7, CK8, CK18 as well as $\mathrm{S}-100$ protein, smooth muscle actin , calponin and vimentin .Basal and myoepithelial cell markers,such as p63, calponin, CK14, and CK5/6 are positive in all tumors with variable proportions [7]. Expression of galectin-3, CK19, and HBME-1 was also seen in a study [8].In our case the tumor stained positive for pancytokeratin , cytokeratin 7 ,vimentin, S100 and negative for p63, calponin, TTF-1, and thyroglobulin making it consistent with CATMSG . The most important differential diagnosis of CATMSG is PLGA, papillary carcinoma of the thyroid gland, adenoid cystic carcinoma. CATMSG lacks the cysts and deeply eosinophilic colloid associated with PTC and reliably stains negative for TTF-1 and thyroglobulin markers and positive for cytokeratin, smooth muscle actin, and S-100 protein. The tumour grows beneath the surface epithelium and infiltrates soft tissue. It is divided by fibrous septa into lobules, which are solid or cribriform The nuclei are uniform, pale and often overlap, closely mimicking those of papillary carcinoma of the thyroid [9]. Thus PLGA by location (i.e. most often arising on the tongue), cytology represented by hybrid myoepithelial-secretory cells, histological architecture, and behavior with frequent metastases at the time of presentation of the primary tumor makes it unique and special type of PLGA. Treatment consists of complete surgical excision as was done in our case. Neck dissection should be added for those patients with cervical adenopathy.

\section{Conclusion}

In conclusion CATMSG appears to be a distinct tumor entity presently considered as a variant of PLGA as per WHO classification. It is unique in its location, presence of secretory myoepithelial cells, histological architecture with characteristic nuclear features, indolent behavior, cervical lymph node involvement at the time of presentation.

\section{References}

1. Michal M, Ska'lova' A, Simpson RHW, Raslan WF, Curik R,Leivo I, Mukensnabl P. Cribriform adenocarcinoma of the tongue: a hitherto unrecognized type of adenocarcinoma characteristically occurring in the tongue. Histopathology. 1999;35:495-501. doi: 10.1046/j.1365-2559.1999.00792.x.

2. Polymorphous low-grade adenocarcinoma.In: EI-Naggar AK, Chan JKC, Grandis JR, Takata T, Slootweg PJ .World Health Organization Classification of Tumours. Pathology and genetics of head and neck tumours. Lyon: IARC Press; 2017.p. 167-8.

3. Majewska HI, Skálová A, Weinreb I, Stodulski D, Dziadziuszko K, Stankiewicz C,Biernat W. Giant cribriform adenocarcinoma of the tongue showing PRKD3 rearrangement. Pol J Pathol 2016; 1(1):84-90.DOI:10.5114/pjp.2016.59223

4. Gailey MP, Bayon R, Robinson RA: Cribriform adenocarcinoma of minor salivary gland: a report of two cases with emphasis on cytology. Diagn Cytopathol 2014; 42: 1085-1090.

5. Laco J, Kamardova K, Vitkova P, Sehnalkova E, Dvorakova S, Vacalavikova E, Sykorova V, Kaspirkova J, Skalova A, Ryska A: Cribriform adenocarcinoma of minor salivary glands may express galectin-3, cytokeratin 19, and HMBE1 and contains polymorphisms of RET and H-RAS protooncogenes. Virchows Arch 2012; 461: 531-40.

6. Skalova A, Sima R, Kaspirkova-Nemcova J, Simpson RHW, Elmberger G, Leivo I, Di Palma S, Jirasek T, Gnepp DR, Weinreb I, Perez-Ordonez B, Mukensnabl P, Rychly B, Hrabal P, Michal M. Cribriform adenocarcinoma of minor salivary gland origin principally affecting the tongue: characterization of new entity. Am J Surg Pathol. 2011;35:1168-1176. doi: 10.1097/PAS.0b013e31821e1f54.

7. Michal M, Kacerovska D, Dmitry V. Kazakov DV.Cribriform Adenocarcinoma of the Tongue and Minor Salivary Glands: A Review.Head Neck Pathol. 2013 ; 7, 1: 3-11

8. Laco J, Kamardova K, Vitkova P, Sehnalkova E, Dvorakova S, Vacalavikova E, Sykorova V, Kaspirkova J, Skalova A, Ryska A: Cribriform adenocarcinoma of minor salivary glands may express galectin-3, cytokeratin 19, and HMBE1 and contains polymorphisms of RET and H-RAS protooncogenes. Virchows Arch 2012; 461: 531-40.

9. Luna MA, Wenig BM. Polymorphous low-grade adenocarcinoma. In: Barnes EL, Eveson JW, Reichart P, et al., editors. World Health Organization Classification of Tumours. Pathology and genetics of head and neck tumours. Lyon: IARC Press; 2005. p. 223-4.

*Corresponding author:

Dr. Sohaila Fatima, Deptt. of Pathology, King Khalid University, Abha,KSA.

Phone: +91 0966-502184094

Email: sohailafatima@gmail.com

Financial or other Competing Interests: None. 